\title{
O BRASIL E A UNASUL: UM PROCESSO DE CONSTRUÇÃO DE LIDERANÇA E INTEGRAÇÃO REGIONAL, de José Ricardo
} Martins ${ }^{1}$

\author{
Alessandro Cavassin Alves ${ }^{2}$
}

- Enviado em 18/01/2016

- Aprovado em 14/02/2016

O trabalho de José Ricardo Martins discute o importante tema da "construção de liderança e integração regional" por parte do Brasil na América Latina neste novo contexto mundial, sob uma nova dinâmica da geopolítica internacional e de globalização, a partir do início do século XXI, que reconfigurou a influência dos países no mundo. E nesta "construção" se destaca, por exemplo, as iniciativas do Brasil em relação à Unasul (União das Nações Sul-Americanas, em vigor desde 2008), a Unila (Universidade da Integração Latino Americana) e a IIRSA (Iniciativa para a Integração da Infraestrutura Regional Sulamericana), como "resultados da política de liderança e de integração regional conduzida pelo Brasil”" (MARTINS, 2011, p.15).

O autor apresenta, então, o significado desta nova configuração de poder que emergem com os chamados "blocos econômicos" ou "blocos regionais" e com as características próprias da globalização no século XXI e seu impacto sobre o Estado-nação. Afinal, citando o grupo de Lisboa sobre o tema da globalização (SANTOS, 2005), Martins conclui que o "Estado-nação não é mais uma entidade totalmente independente que pode tomar suas ações e desenvolver suas políticas independentemente do mundo exterior. $\mathrm{Na}$ atual fase da globalização isto parece não ser mais

\footnotetext{
${ }^{1}$ Dissertação de autoria de José Ricardo Martins, defendida no Programa de Pós-Graduação em Sociologia da UFPR, na linha Sociedade e Estado, em 2011, sob orientação do Prof. Dr. Ricardo Costa de Oliveira. Versão completa disponível na Biblioteca Digital da UFPR - http://www.humanas.ufpr.br/portal/pgsocio/files/2012/12/Vers\%C3\%A3o-Digital-daDisserta\%C3\%A7\%C3\%A30.pdf. Acesso em 19/09/2015.
}

${ }^{2}$ Doutor em Sociologia. Professor na FASBAM (Faculdade São Basílio Magno), Curitiba, PR e SEED (Secretaria de Estado da Educação do Paraná). Endereço eletrônico: alessandrocavassin@gmail.com . 
possível. Suas decisões de política interna, especialmente as econômicas, devem levar em conta o mundo externo e são, ao mesmo tempo, amplamente influenciadas por este" (MARTINS, 2001, p.26-27). Porém, ao mesmo tempo, o autor defende que o Estado é "central na organização políticoeconômico-social de uma nação", mas por sua vez tem de abdicar "parcialmente de sua soberania para tornar-se mais forte e competitivo em agrupamento regional" (Ibidem, p.32).

Neste sentido, José Ricardo Martins realiza uma detalhada revisão bibliográfica a respeito dos temas "potência regional, liderança regional e regionalismo manifestado por meio da integração regional" (Ibidem, p.33), pois há uma nova configuração de forças entre as nações que se faz necessário entender, principalmente pós fim da Guerra Fria em que a configuração geopolítica entre comunistas e capitalistas desaparece.

Portanto, os inúmeros estudos sobre o processo de integração regional que foram sendo produzidos ao longo do século $\mathrm{XX}$, bem como suas diferentes perspectivas de análises, são analisados pelo autor. E a referência aos blocos de integração concretos, como a União Europeia, a Comunidade Andina de Nações, o Mercosul, entre muitos outros, possibilitam aos pesquisadores terem uma visão melhor do significado, da diferença e da dinâmica destes pactos regionais, inclusive sob o olhar comparativo. E, assim, cada bloco de integração acaba tendo características próprias, de acordo com a realidade e necessidades que os países membros visam suprir ou enfrentar. E que devem levar, como se demonstra no trabalho, uma integração que ultrapasse os aspectos econômicos e avance igualmente para uma integração cultural, educacional, política, de infraestrutura, de segurança etc.

É neste sentido que se pergunta sobre o papel do Brasil na integração da América Latina. Afinal, o Brasil já vem se destacando em âmbito internacional como liderança, com inúmeras atividades que o projetaram neste cenário. E estas ações a nível global fizeram com que as nações e mesmo os organismos internacionais tivessem o Brasil como líder, tanto devido sua força econômica quanto sua posição como grande nação na América do Sul.

Mas para se compreender tal movimento de integração latino americana é necessário observar a história conjunta destes países, e pensar de início nas inúmeras diferenças que os fizeram distantes e, ao mesmo tempo, que voltassem "às costas" uns aos outros, mesmo que vizinhos. Por isso, a dificuldade de se considerar a liderança de um destes países, como o do Brasil, país mais forte economicamente deste continente. Liderança que se pensa a partir da própria necessidade do novo contexto da globalização, do pós Guerra Fria, de enfrentamento dos desafios econômicos 
mundiais e, que também, não se deve confundir com a imposição de vontades específicas por parte do país líder ou do país "mais forte” sobre os países envolvidos no processo de integração.

Foi, então, a partir da metade do século XX que se iniciou um processo de discussão da integração entre os países latino americanos, desde a América Central até a América do Sul, que se aprofunda apenas na década de 1990 com a constituição de blocos regionais, como o Mercosul (que iniciou a partir de 26/03/1991), e finalmente, com a cúpula dos 12 países sulamericanos, a Unasul, encontro que ocorreu em Brasília, em agosto de 2000. Inicia-se, neste mesmo ano, a discussão da integração da infra-estrutura com a Iniciativa de Integração Regional Sulamericana (IIRSA). Em 2004 foi criada a Comunidade Sulamericana de Nações. Portanto, como salienta Martins, "os ideários e imaginários de construção de uma grande pátria sulamericana (de Simon Bolívar, Antônio José Sucre e de José de San Martín) misturam-se ao pragmatismo da necessidade de união para fazer frente à globalização" (Ibidem, p. 66).

A Unasul, liderada pelo Brasil, se encaminha para ter os moldes institucionais do Mercosul, na qual se destaca a autonomia e o universalismo como suas características. Autonomia dos países envolvidos frente ao acordo, privilegiando seus interesses, e ao mesmo tempo, o universalismo, que significa a abertura da pluralidade de interesses do Estado e da sociedade frente à internacionalização. Enfim, "baixa institucionalização e relevância na intergovernamentalidade, com pouca burocracia" (Ibidem, p. 70), eis como pode estar sendo construído a Unasul. Por isso, este modelo de institucionalização do bloco, dificulta igualmente um processo de integração de forma mais profunda, como a redução das assimetrias dentro do próprio bloco, bem como, políticas sociais, intercâmbio cultural e de informações, fortalecer a democracia e a cidadania, entre outros elementos, que são objetivos da Unasul. E ao longo da primeira década do século XXI, inúmeras reuniões destes chefes de Estados vêm acontecendo para aprofundar o debate sobre esta integração. Conselhos como de Defesa, Saúde, Energético, entre outros “são embriões da institucionalização do bloco, mas não podem ser considerados como instituições da Unasul, pois não têm poder de tomada de decisão. Eles discutem o encaminhamento de questões e propostas e fornecem sugestões aos chefes de Estado" (Ibidem, p. 72). Eis a característica da baixa institucionalização deste bloco, que, como dito, implica obstáculos a uma integração maior. Apesar de que, "esta persegue objetivos semelhantes aos da União Europeia. O projeto é de se tornar uma Zona de Livre Comércio em 2019” (Ibidem, p.75). E, desde 2011, a Unasul já possui o seu Tratado Constitutivo de la Unión de Naciones Suramericanas (UNASUR, Quito, 11 de marzo 2011). 
No subcapítulo "um projeto político para a América do Sul”, o autor, então, passa a discutir o porquê do Brasil investir na Unasul, na IIRSA e na Unila. E para responder a esta questão, Martins busca entender os discursos da diplomacia do Brasil a partir do ano 2000, quando o país passa a ter uma maior representatividade também em âmbito internacional.

Quanto a Unila, Martins destaca que "a integração regional é o cerne e o foco de todas as atividades e preocupações da Unila, pois ela carrega no seu nome a marca da integração. E justamente a missão da nova universidade é contribuir para o processo de integração regional latinoamericano por meio do conhecimento compartilhado e da cooperação solidária entre universidades e centros de pesquisa da América Latina" (ibidem, p.87).

E assim, conceitos interessantes passam a ser debatidos pelo autor como forma de entender como o Brasil busca "construir" sua liderança na América. São os conceitos de soft power em oposição ao conceito de hard power.

Em suma, a criação da Unila evidencia esse esforço de liderança e de integração regional, através do exercício do soft power, do poder brando. Todos os documentos institucionais da Unila voltam-se à integração. As autoridades brasileiras compreenderam que a integração regional acontece de forma plena por meio da mobilidade das pessoas, da criação de uma mentalidade comum de cooperação, espírito de pertença, conquista das mentes e corações, integração física (por meio dos projetos da IIRSA) e da construção de uma comunidade de desenvolvimento e de segurança (por meio dos diversos conselhos da Unasul, especialmente o CDS - Conselho de Defesa Sulamericano) (Ibidem, p. 95).

Com a instituição de uma Universidade construída geograficamente na fronteira entre Paraguai, Argentina e Brasil, busca-se consolidar, através do soft power, a liderança brasileira, pelo viés cultural e científico, e menos pela imposição da força, tanto de armas como de recursos financeiros, como o conceito de hard power sugere como forma de exercer o predomínio e a influência sobre outros países.

E, assim, José Ricardo Martins discute esta opção estratégica brasileira de voltar-se para a América do Sul, buscando estabelecer uma integração regional, e se ele exerce algum tipo de liderança neste processo de criação da Unasul.

Como exposto, o Brasil conta com uma ampla aceitação internacional de seu papel de líder na América do Sul, sendo a mesma timidamente manifestada no âmbito intra-regional. São várias iniciativas de líder dentro da própria América do Sul, mas não gera consenso e adesão. Torna-se claro que, por falta de hard power [meios militares e financeiros], torna-se mais difícil o país exercer a liderança. O que se realça na atuação brasileira é a diplomacia, tendo destaque a presidencial, trabalhando seu soft power ou a diplomacia consensual, como veremos mais adiante (Ibidem, p.111). 
Portanto, "como o Brasil não possui hard power à altura de sua estatura e de suas aspirações regionais e globais, a solução que se apresenta ao país seria exercer sua liderança pelo soft power. O exercício da liderança baseado apenas no soft power é mais difícil de ser praticada, mas não impossível” (Ibidem, p.123). Eis o "desafio do brasileiro: liderar pelo soft power", de acordo com José Ricardo Martins.

Como já demonstrado anteriormente, o Brasil é uma potência média aceita pela comunidade internacional, mas que ocupa um espaço na periferia da elite global. Para um país de status de potência média, a literatura (Brands, 2010), presume algumas limitações e estabelece algumas opções para o exercício da liderança. Com limitados recursos, o soft balacing, a formação de coalizões e o regionalismo (formação de bloco regional) são as melhores opções para o exercício de liderança de uma potência média, segundo Hal Brands (2010) (Ibidem, p.124).

Isto levaria ao conceito de "hegemonia consensual", que significa o consentimento dos liderados em estratégias de ação que beneficiam a todos, como é o caso da criação do conselho de defesa sulamericano pela Unasul, algo estratégico e importante para todas as nações do bloco, ou mesmo a IIRSA, integrando os países com redes de energia, transporte e telecomunicações, e isto sendo o Brasil o líder deste processo. Uma hegemonia que ganha força pelo consentimento dos liderados e não pela ameaça e imposição (Ibidem, p. 126). Aqui, destaca-se, também, o papel da diplomacia brasileira. Enfim, seria a construção de uma "liderança pela autoridade e pela cordialidade".

\begin{abstract}
Distinto da coerção, neste conceito a autoridade é baseada na legitimidade e nas obrigações morais que são os vetores mobilizadores dos seguidores. Para construir e manter autoridade, segundo Lake, há dois requisitos necessários que devem ser observados: (i) prover ordem social que beneficie os subordinados e, por sua vez, os una a esta ordem, e (ii) prover credibilidade - não para explorar os seguidores, uma vez que consentiram à autoridade (Lake, 2006). Há de se ressaltar que quando a integração é pautada por interesses próprios, egoísticos, o país - neste caso o Brasil - é visto como imperialista. Consciente desta rotulação que o país sofre, a diplomacia brasileira pratica, para com seus vizinhos, a política da cordialidade. Desta forma, o país evita recorrer a mecanismos internacionais para fazer valer seus direitos, em vez disso pratica a cordialidade através de acordos abaixo de sua capacidade de negociação. Como exemplos, pode-se citar os casos da Bolívia (questão das refinarias), Equador (questão das construtoras e dívida com o BNDES), Paraguai (questão dos royalties de Itaipu) e mesmo os acordos e cotas comerciais com a Argentina durante a crise daquele país no início dos anos 2000 (Ibidem, p.129)
\end{abstract}

Enfim, José Ricardo Martins conclui com o título do "difícil caminho da liderança do Brasil na América Latina". E destaca que "verificamos que há reconhecimento mundial unânime que o Brasil é o líder natural da região e esta liderança deve ser exercida. Contudo, também verificamos que a liderança brasileira não é reconhecida por parte dos países da região (os 
potenciais liderados) ou se tem receio de aceitá-la e quando é aceita, trata-se de situações pontuais" (Ibidem, p.133).

Enfim, a estratégia do Brasil de liderar pelo soft power, buscando a hegemonia consensual, poderá, ao longo dos próximos anos, consolidar uma maior e necessária integração da América Latina? E, outra questão, sempre posta a esta discussão, que não deixa de ser abordada pelo autor, são os "desafios domésticos à liderança regional". Afinal, qual é o preço que o Brasil paga para construir sua liderança a âmbito regional e mundial? Qual o preço que sua população tem de suportar para que uma liderança se consolide ou se imponha na América do Sul? E, portanto, se tal iniciativa é válida e fundamental? Mas, como o próprio trabalho de José Ricardo Martins aponta, apostar na integração regional talvez seja mais um caminho para se enfrentar também os desafios domésticos e ainda, de seus "vizinhos" latino americanos. É buscar consolidar uma justiça social mais equitativa de forma conjunta para este amplo e rico continente.

\section{REFERÊNCIAS}

BRASIL, Mercosul. Disponível em: http://www.mercosul.gov.br/. Acesso em 19/09/2015.

BRASIL, Unila. Disponível em: https://www.unila.edu.br/. Acesso em 19/09/2015.

DONGHI, Túlio Halperin. História da América Latina. $4^{\text {a } e d . ~} 1^{\text {a }}$ reimpressão. Rio de Janeiro: Paz e Terra, 2011.

MARTINS, José Ricardo. O Brasil e a UNASUL: Um processo de construção de liderança e integração regional. Dissertação em Sociologia Política e Relações Internacionais. Curitiba, UFPR, 2011. http://www.humanas.ufpr.br/portal/pgsocio/files/2012/12/Vers\%C3\%A3o-Digital-daDisserta\%C3\%A7\%C3\%A3o.pdf. Acesso em 19/09/2015.

ONUKI, Janaina. O Brasil no sistema internacional. In: MORAES, Amaury César. Sociologia: ensino médio. Brasília: Ministério da Educação, Secretaria de Educação Básica, 2010.

SANTOS, Boaventura de Souza (org.). A globalização e as Ciências Sociais. $3^{\text {a }}$. ed. São Paulo: Cortez, 2005.

UNASUR. Tratado Constitutivo de la Unión de Naciones Suramericanas. Quito: Secretaria General de UNASUR, 2011. $\quad$ Disponível em: http://www.unasursg.org/images/descargas/DOCUMENTOS\%20CONSTITUTIVOS\%20DE\%20U NASUR/Tratado-UNASUR-solo.pdf. Acesso em 05/10/2015. 